\title{
Special Issue Preface
}

\section{Di Vaio Assunta}

Department of Law, University of Naples "Parthenope", Naples, Italy

\section{Email address:}

susy.divaio@uniparthenope.it

\section{To cite this article:}

Di Vaio Assunta. Special Issue Preface. Journal of Human Resource Management. Special Issue: Challenges and Opportunities in the Performance Measurement and Control Systems of Human Resources Management for the Services Industry. Vol. 3, No. 2-1, 2015, doi: 10.11648/j.jhrm.s.2015030201.17

\section{Personal Profile of Lead Guest Editor}

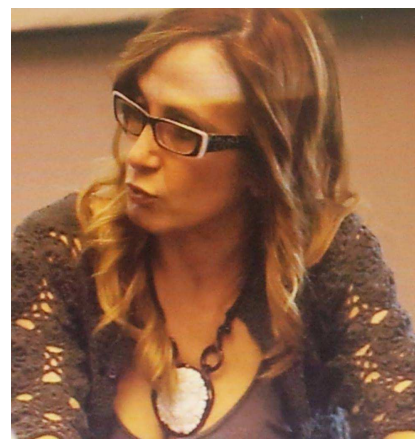

\section{Name: Assunta Di Vaio}

\section{Education}

2003 - 2007 Ph.D. in Business Administration at Cà Foscari University of Venice, Italy

2001 - 2002 MSc in Service Management - Specialization: Logistics and Transport at University of Modena and Reggio Emilia, Italy

\section{Summary of Employment}

2008 to present $\quad$ Professor in Business Administration, University of Naples Parthenope, Italy

2009 - 2012 Visiting Professor at University College of London (UCL), Visiting Professor at University of Las Palmas de Gran Canaria (Spain)

1999 - $2000 \quad$ Research scholarship, Institute for Service Industry Research (IRAT), National Research Council (CNR) in Italy 


\section{Preface}

In the last decades, the services industry has faced new challenges in the global economy recognizing more and more the crucial role of the human capital. Globalization of the market, internationalization of the firms, high innovativeness in the products and processes, dematerialization of the production process represent only a few challenging phenomena that the services firms have to manage. Human resources in the services industry play always a key role but, in most cases, they still have been conceived merely as costs within the accounting information systems.

In this context, it seems necessary to identify and investigate a set of tools able to support the strategic human resources management suggesting the right direction in their improvement and evaluation. Innovative and sophisticated strategic and managerial tools are needed to harness the great potential of the human resources significantly contributing to the firm performance. On one side, scholars and practitioners tend to adapt the potential of human resources to the organisational needs increasing their level of stress with high burnout risks; on the other side, human resources operate in a more technological and competitive workplace and need continuously to enrich and change their skills and competences.

The aim of this special issue is to extend the conceptual and empirical research on the Human Resource Management (HRM) focusing on the strategic and managerial tools that allow either improving and assessing the human resources or measuring and monitoring the specific contribution of human resources to the performance. Top management can be supported from these tools developed thanks to data and information systems.

The services industry represents an interesting research area to investigate the described phenomena due to its specific characteristics and challenges. The following sectors have been analyzed in six manuscripts in this special issue: the health care setting, the maritime industry, the public administration, and the software industry.

The first two papers provide applications in the health care setting, investigating two specific topics, on one side, the human resources evaluation system through a qualitative approach, and, on the other side, the implementation of IT for the assessment in the development of the health care professionals. Instead, the maritime industry is examined in the third manuscript, which concerns the role of management and control systems in the implementation of international regulations about the safety and welfare of workers on board ships. Furthermore, the forth manuscript applies the Balanced Scorecard to measure and evaluate human resources performance in the US public sector. Then, the fifth paper regards the study of the impact of management accounting for the improvement of the human resources management in the software industry. Finally, the sixth one examines the disclosure on human capital in the Italian listed public utilities.

The conceptual and empirical manuscripts in the special issue represent significant contributions in which different research perspectives of analysis have been adopted developing specific topics, such as performance assessment and measurement in HRM; implications of innovative managerial tools and information technology in the improvement and evaluation of human resources; planning, control systems and reporting in HRM; human capital in the financial statements. Indeed, the special issue evidences a multidisciplinary research approach, in which several research areas have been involved: the business administration, the managerial accounting, the organization science, and the management information systems. 